\title{
BMJ Open 25-year trends in gender disparity for obesity and overweight by using WHO and IOTF definitions among Chinese school-aged children: a multiple cross-sectional study
}

\author{
Yi Song, ${ }^{1,2}$ Hai-Jun Wang, ${ }^{1}$ Bin Dong, ${ }^{3}$ Jun Ma, ${ }^{1}$ Zhiqiang Wang, ${ }^{1,3}$ Anette Agardh ${ }^{2}$
}

To cite: Song Y, Wang H-J, Dong B, et al. 25-year trends in gender disparity for obesity and overweight by using WHO and IOTF definitions among Chinese school-aged children: a multiple cross-sectional study. BMJ Open 2016;6: e011904. doi:10.1136/ bmjopen-2016-011904

- Prepublication history and additional material is available. To view please visit the journal (http://dx.doi.org/ 10.1136/bmjopen-2016011904).

Received 14 March 2016 Revised 29 August 2016 Accepted 31 August 2016

\section{CrossMark}

For numbered affiliations see end of article.

Correspondence to

Professor Jun Ma; majunt@bjmu.edu.cn and Professor Hai-Jun Wang; whjun1@bjmu.edu.cn

\section{ABSTRACT}

Objectives: We sought to explore 25-year trends of gender disparity in the prevalence of obesity and overweight both in urban and rural areas among Chinese children from 1985 to 2010.

Methods: Data included 1280239 children aged 7-18 years enrolled in the Chinese National Survey on Students's Constitution and Health (CNSSCH), which is the largest nationally representative sample of schoolaged children in China. Obesity and overweight were defined according to both WHO and the International Obesity Task Force (IOTF) definitions. Logistic regression was used to estimate the prevalence $O R$ (POR) of gender for obesity and overweight prevalence in different surveys.

Results: The prevalence of obesity increased (WHO definition: from $0.10 \%$ to $4.3 \%$; IOTF definition: from $0.03 \%$ to $2.2 \%$ ) over the past 25 years in urban and rural areas among Chinese children and it was much higher among boys than girls at each survey point $(p<0.01)$. The increasing trend was significant in all age subgroups $(p<0.01)$. Although the prevalence of obesity continuously increased in boys and girls, the changing pace was more rapid in boys than in girls. PORs of boys versus girls for obesity also increased over time, and the estimates of PORs were higher in urban areas than in rural areas at each survey point. Conclusions: The gradually increasing gender disparity in urban and rural areas suggests that the prevalence of obesity and overweight in boys, and especially in urban boys, contributes to a large and growing proportion of obese and overweight children.

\section{INTRODUCTION}

Childhood obesity is becoming a topic of great concern due to the rising prevalence of this condition across the globe. ${ }^{1-3}$ A previous study predicted that by 2010 , over $40 \%$ of children in the North American and Eastern Mediterranean WHO regions, $38 \%$ in the European region, 27\% in the Western Pacific

\section{Strengths and limitations of this study}

- The study population was derived from national surveys from 1985 to 2010, and a consistent stratified cluster sampling procedure and method of measurement contributed to the comparability of the data from different survey years.

- We provided the prevalence of obesity and overweight using both the WHO and International Obesity Task Force definitions at the national level, making international comparisons possible.

- This is one of the largest reports in Asian children on gender disparity related to the temporal change in obesity and overweight prevalence in urban and rural areas, thus providing new information about $\mathrm{OR}$ prevalence trends for obesity in boys versus girls.

- Some 15-18-year-old adolescents who could not attend senior high school were not investigated in the school-based national survey.

- Some risk factors that were not measured in this study, such as family income, parents' body mass index and number of siblings, may also contribute to the trends in obesity.

region and $22 \%$ in the South-East Asian region would be overweight/obese. ${ }^{4}$ China has now joined the world epidemic of obesity, in which the prevalence of childhood overweight has markedly increased from $1.11 \%$ in 1985 to $9.62 \%$ in 2010 , while the prevalence of childhood obesity increased from $0.13 \%$ in 1985 to $4.95 \%$ in $2010 .^{5}$

Worldwide, the combined prevalence of overweight and obesity rose by $47.1 \%$ for children between 1980 and 2013. ${ }^{6}$ Since 1980, the prevalence of overweight and obesity in developed countries has increased from $16.9 \%$ to $23.8 \%$ in boys and $16.2 \%$ to $22.6 \%$ in girls; similarly, the prevalence has also increased in developing countries from $8.1 \%$ to $12.9 \%$ in boys and from $8.4 \%$ to 
$13.4 \%$ in girls. ${ }^{6}$ Although the obesity prevalence in either boys or girls has markedly increased in different parts of the world, gender differences in prevalence have been observed. In contrast to the USA, UK and Cuba, in many countries or regions, such as Belgium, Canada, Greece, India, Japan, mainland China and East Asia, the prevalence of obesity in boys is higher than that in girls. ${ }^{6-7}$ Previous studies showed that gender differences in secular trends in obesity varied in different regions, ethnicities and populations, ${ }^{8-9}$ but few of them focused on how gender disparities in obesity change over time. In China, it has been reported that urban children were more susceptible to obesity than rural children, ${ }^{10-11}$ and the changing pace of obesity prevalence was faster in boys than in girls in urban Chinese children. ${ }^{11}$ However, the question still remains as to whether this trend exists in rural areas in China and how gender disparities in obesity and overweight change over time in urban and rural areas. This study may therefore have implications for health policymakers and researchers considering targeted intervention strategies for obesity prevention.

This study used data from the recent Chinese National Survey on Students' Constitution and Health (CNSSCH, 2010), ${ }^{12}$ and earlier surveys (CNSSCH, 1985, 1995, 2000, 2005) ${ }^{13-16}$ these are a series of nationally representative surveys among school-aged children in China. The objectives of our study were to: (1) describe the secular trend in the prevalence of obesity and overweight over the past 25 years among Chinese school-aged children; (2) identify whether the gender disparity in the prevalence of obesity and overweight became larger or smaller, that is, whether the pace of increase was different between boys and girls; and (3) assess whether the gender disparity showed different trends in urban and rural areas.

\section{PARTICIPANTS AND METHODS}

\section{Participants}

Data were obtained from the 1985, 1995, 2000, 2005 and 2010 cycles of the CNSSCH, a joint project of the Ministries of Education, Health, Science and Technology, the State Ethnic Affairs Commission, and the State Sports General Administration of People's Republic of China. ${ }^{12-16}$ The sampling procedure, as previously described in detail, ${ }^{5} 1117$ was the same in all CNSSCH at each time point. The participants were primary and high school students aged 7-18 years, who were selected from the same areas in each province from 1985 to 2010. This study only included participants of Han ethnicity, who account for $92 \%$ of the total Chinese populations, from 26 mainland provinces and 4 municipalities of mainland China, excluding Tibet (where Han ethnicity is a minority). The sample sizes in CNSSCH in different years ranged from 12193 to 25678 in each gender-specific and age-specific subgroup, and the ratio of boy/girl or urban/rural was $\sim 1: 1$ in each survey. Thus, a total of 1280239 participants were included in the analyses, and all children had complete data on age, sex, areas, weight and height (see online supplementary table S1). The sample size in each subgroup was larger in 1985 than in the subsequent years, because the Chinese government consulted relevant experts after the 1985 survey and consequently revised the sample size that was deemed to be sufficient for statistical analyses. To ensure national representation, the surveys after 1985 proposed to select the same schools as in 1985, but fewer students in each school; thus, more than $85 \%$ of the schools sampled were identical in each survey. All participants were selected by stratified cluster sampling, in that sampling took place in classes randomly selected from each grade in the selected school; thus the sample size in sex-specific and age-specific subgroups varied slightly in each survey after 1985. All eligible participants had lived in the same area for at least 1 year and received a medical examination by physicians before measurement. Students were excluded from the survey if they had at least one of the following conditions: (1) serious organ diseases (heart, lung, liver and kidney); (2) abnormal physical development, for example, pygmyism and gigantism; (3) physical impairment or deformity, such as severe scoliosis, chicken breast, limp, obvious O leg and X leg; (4) acute diseases or high fever, diarrhoea and other acute diseases during the past month, and not yet recovered. Each province had an equal sample size from three socioeconomic classes ('upper', 'moderate' and 'low') at the regional level. Five aspects were taken into consideration in defining the socioeconomic status of the regional level: regional gross domestic product, total yearly income per capita, average food consumption per capita, natural growth rate of population and the regional social welfare index. $^{5} 1117$

\section{Measures}

Height $(\mathrm{cm})$ and weight $(\mathrm{kg})$ were measured, using the same types of instruments according to the standard procedures in all survey sites. ${ }^{12-16}$ Participants were required to wear only light clothing and stand straight, barefooted and at ease when being measured. Weight was measured to the nearest $0.1 \mathrm{~kg}$ with a standardised scale and height was measured to the nearest $0.1 \mathrm{~cm}$ with a portable stadiometer. Both the scales and stadiometers were calibrated before use. The measurements were generally carried out at the same time of the day during the survey. Body mass index (BMI) was calculated as body weight $(\mathrm{kg})$ divided by height $(\mathrm{m})$ squared $\left(\mathrm{kg} / \mathrm{m}^{2}\right)$. BMI-for-age Z-score is a quantitative measure of the deviation of a specific BMI value from the mean of that population, and was calculated with the WHO (WHO 2007) references. ${ }^{18}$ Obesity and overweight were defined using the growth references of BMI-for-age Z-score for 5-19 years developed by WHO: thinness: <-2SD; overweight: >+1SD; obesity: >+2SD. ${ }^{19}$ To enable comparisons with other studies, we also used 
definitions from the International Obesity Task Force (IOTF) ${ }^{20}$ Measurements at the survey site were conducted by a team of field professionals who had passed a training course in anthropometric measurements.

\section{Statistical analyses}

We present prevalence estimates for obesity and overweight in different survey years according to gender, urban-rural areas and age groups. To test for trend across years, we regressed survey years as an ordinal variable on the binary outcome of obesity. To assess gender differences at each time point, we used logistic regression to estimate the prevalence OR (POR) for obesity and overweight in boys versus girls, and estimated the PORs by age group with adjustment for urban-rural area and socioeconomic status in the models. The design effect of cluster sampling by school was also taken into account in the model. All analyses were conducted by using Stata V.12.1. A two-sided $p$ value $<0.05$ was considered significant.

\section{RESULTS}

Trends in the prevalence of obesity and overweight among Chinese children

The prevalence of obesity increased over the past 25 years in Chinese children according to both the WHO and IOTF definitions and was much higher among boys than girls at each survey point $(\mathrm{p}<0.01)$. When stratified by urban-rural area, the urban children showed higher prevalence of obesity than their rural peers; furthermore, the prevalence of obesity in either urban or rural boys contributed more to the growing proportion of obese children than did the prevalence of obesity in girls. The combined prevalence of obesity and overweight showed a similar pattern except for the 1985 CNSSCH (table 1).

\section{Trends in the prevalence of obesity and overweight by age group}

Table 2 shows that highest prevalence of obesity was observed in the 7-9-year-old subgroup, and the highest combined prevalence of obesity and overweight was observed in the 10-12-year-old subgroup in boys. The prevalence of obesity in all age subgroups showed an increasing trend over time in boys as well as in girls $(p<0.001)$. Both the increments per year and ratio increments of the prevalence of obesity between two adjacent surveys were higher in boys than in girls at each survey point, as was the prevalence of obesity and overweight combined (see online supplementary table S2).

\section{PORs of boys versus girls for obesity and overweight}

Higher PORs of obesity were observed between 1985 and 2010 in urban and rural areas (figure 1 and see online supplementary table S3). The interaction between gender and time was statistically significant $(p<0.01)$. We estimated the PORs for obesity in different years among various age subgroups with similar trends in PORs observed (data not shown). When PORs for obesity were assessed after stratification by urban-rural area, the POR estimates were higher in urban areas than those in rural areas at each survey point. However, the increase in PORs for obesity in rural areas was more rapid than the increase in urban areas over time (figure 1 and see online supplementary table S3). Although in the $1985 \mathrm{CNSSCH}$ the gender differences for obesity and overweight showed inconsistent directions in urban and rural areas according to the WHO definition; the trends of PORs of boys versus girls showed a similar pattern (figure 1 and see online supplementary table S3). In the analyses stratified by socioeconomic class, the temporal trends of POR in three different regions ('upper', 'moderate' and 'low') were similar to the trends in the total sample (data not shown).

\section{DISCUSSION}

This study indicated that the prevalence of obesity and overweight increased dramatically between 1985 and 2010. These findings were consistent with previous reports showing that the prevalence of general obesity and abdominal obesity increased significantly among Chinese children age 6-17 years from 1993 to 2009; general obesity (including overweight) rose from $6.1 \%$ to $13.1 \%$ and abdominal obesity from $4.9 \%$ to $11.7 \% .{ }^{21}$ The trends of obesity and overweight were also in agreement with previous studies in other countries. ${ }^{6-8}$ However, this study is the first to report temporal changes in gender disparities concerning the prevalence of obesity and overweight in urban and rural areas of China.

In the present study, we found that the gender differences in the prevalence of obesity and overweight became larger and larger. The year 1985 can be considered as the beginning of a childhood overweight and obesity epidemic in China, ${ }^{5}$ and at that time, the prevalence of obesity and overweight was very low. In the mid-1980s the Chinese government initiated a series of food policies for liberalising pricing and food procurement, which improved the food supply and made diverse foods available. ${ }^{5} 22$ In 1993, the government abolished grain rationing systems, and afterwards, the food supply has remained adequate and stable and has been more and more abundant. ${ }^{23}$ The abundant food supply may have provided a basis for the childhood obesity epidemic, and in the present study, we also found that there was a rapid increase in the prevalence of obesity and overweight from 1985 to 2010.

Several studies have observed that there is a gender difference in obesity prevalence. ${ }^{156}{ }^{11}$ In many Western countries the prevalence of childhood obesity was higher in girls, whereas, in Asian countries, especially in China, the prevalence of childhood obesity was higher in boys than in girls. ${ }^{6}{ }^{11}$ In Taiwanese children aged 6-18 years, the percentage of overweight boys and obese students increased from $5.7 \%$ to $14.2 \%$ and from $7.9 \%$ 
Table 1 Obesity prevalence for all children $7-18$ years of age by survey year

\begin{tabular}{|c|c|c|c|c|c|c|}
\hline \multirow[b]{2}{*}{ Category } & \multicolumn{3}{|c|}{ WHO definition, \% (95\% Cl) } & \multicolumn{3}{|c|}{ IOTF definition, \% (95\% Cl) } \\
\hline & Total & Boys & Girls & Total & Boys & Girls \\
\hline \multicolumn{7}{|l|}{ Urban areas } \\
\hline \multicolumn{7}{|l|}{ Obesity } \\
\hline 1985 & $0.16(0.14$ to 0.18$)$ & $0.24(0.21$ to 0.27$)$ & 0.08 (0.06 to 0.10$)$ & 0.05 (0.04 to 0.05$)$ & 0.05 (0.04 to 0.07$)$ & $0.04(0.02$ to 0.05$)$ \\
\hline 1995 & $1.5(1.5$ to 1.6$)$ & 2.3 (2.2 to 2.5$)$ & 0.75 (0.67 to 0.82$)$ & 0.68 (0.63 to 0.73$)$ & 0.95 (0.87 to 1.03$)$ & 0.41 (0.36 to 0.47$)$ \\
\hline 2000 & $3.3(3.2$ to 3.4$)$ & $5.1(4.9$ to 5.3$)$ & $1.5(1.4$ to 1.6$)$ & $1.6(1.5$ to 1.6$)$ & $2.4(2.2$ to 2.5$)$ & $0.78(0.71$ to 0.86$)$ \\
\hline 2005 & $4.7(4.6$ to 4.8$)$ & $7.3(7.1$ to 7.5$)$ & $2.0(1.9$ to 2.1$)$ & $2.3(2.2$ to 2.4$)$ & $3.4(3.3$ to 3.6$)$ & $1.2(1.1$ to 1.2$)$ \\
\hline 2010 & $5.6(5.5$ to 5.7$)$ & 9.0 (8.7 to 9.2$)$ & $2.2(2.1$ to 2.4$)$ & $2.8(2.6$ to 2.9$)$ & $4.3(4.1$ to 4.5$)$ & $1.3(1.2$ to 1.3$)$ \\
\hline $\mathrm{p}$ Trend test* & $<0.001$ & $<0.001$ & $<0.001$ & $<0.001$ & $<0.001$ & $<0.001$ \\
\hline \multicolumn{7}{|c|}{ Overweight+obesity } \\
\hline 1985 & 1.5 (1.4 to 1.5$)$ & $1.6(1.6$ to 1.7$)$ & $1.3(1.2$ to 1.4$)$ & 0.88 (0.84 to 0.92$)$ & 0.89 (0.83 to 0.95$)$ & $0.86(0.81$ to 0.92$)$ \\
\hline 1995 & $7.6(7.4$ to 7.8$)$ & $9.7(9.4$ to 10.0$)$ & 5.5 (5.3 to 5.7$)$ & $5.3(5.2$ to 5.5$)$ & $6.6(6.3$ to 6.8$)$ & 4.1 (3.9 to 4.3 ) \\
\hline 2000 & $13.0(12.8$ to 13.2$)$ & $17.2(16.9$ to 17.5$)$ & $8.8(8.6$ to 9.1$)$ & $9.6(9.4$ to 9.8$)$ & $12.4(12.1$ to 12.6$)$ & $6.8(6.6$ to 7.0$)$ \\
\hline 2005 & 16.5 (16.3 to 16.7$)$ & 22.0 (21.7 to 22.3$)$ & $11.0(10.8$ to 11.3$)$ & $12.6(12.4$ to 12.8$)$ & $16.6(16.3$ to 16.9$)$ & 8.5 (8.3 to 8.8$)$ \\
\hline 2010 & $19.0(18.8$ to 19.3$)$ & 25.2 (24.9 to 25.6$)$ & 12.9 (12.6 to 13.2$)$ & 14.5 (14.3 to 14.8$)$ & $19.2(18.9$ to 19.5$)$ & 9.9 (9.6 to 101$)$ \\
\hline $\mathrm{p}$ Trend test* & $<0.001$ & $<0.001$ & $<0.001$ & $<0.001$ & $<0.001$ & $<0.001$ \\
\hline \multicolumn{7}{|l|}{ Rural areas } \\
\hline \multicolumn{7}{|l|}{ Obesity } \\
\hline 1985 & $0.04(0.03$ to 0.05$)$ & 0.05 (0.04 to 0.06$)$ & $0.02(0.01$ to 0.03$)$ & 0.01 (0.01 to 0.02$)$ & 0.01 (0.01 to 0.02$)$ & 0.01 (0.01 to 0.02$)$ \\
\hline 1995 & $0.40(0.36$ to 0.44$)$ & $0.58(0.51$ to 0.65$)$ & 0.21 ( 0.17 to 0.25$)$ & $0.18(0.16$ to 0.21$)$ & $0.24(0.20$ to 0.28$)$ & $0.13(0.10$ to 0.16$)$ \\
\hline 2000 & $1.1(1.1$ to 1.2$)$ & $1.7(1.5$ to 1.8$)$ & 0.57 (0.51 to 0.63$)$ & 0.56 (0.51 to 0.60$)$ & 0.76 (0.68 to 0.83$)$ & $0.36(0.31$ to 0.41$)$ \\
\hline 2005 & $2.0(1.9$ to 2.0$)$ & $3.0(2.8$ to 3.1$)$ & 0.95 (0.87 to 1.03$)$ & 0.89 (0.84 to 0.95$)$ & $1.2(1.1$ to 1.3$)$ & 0.55 (0.49 to 0.61$)$ \\
\hline 2010 & 3.1 (3.0 to 3.2$)$ & $4.8(4.6$ to 5.0$)$ & $1.4(1.3$ to 1.5$)$ & $1.5(1.4$ to 1.6$)$ & $2.2(2.1$ to 2.4$)$ & 0.80 (0.72 to 0.87$)$ \\
\hline $\mathrm{p}$ Trend test* & $<0.001$ & $<0.001$ & $<0.001$ & $<0.001$ & $<0.001$ & $<0.001$ \\
\hline \multicolumn{7}{|c|}{ Overweight+obesity } \\
\hline 1985 & 0.75 (0.71 to 0.79$)$ & $0.53(0.48$ to 0.57$)$ & $0.98(0.92$ to 1.04$)$ & $0.46(0.43$ to 0.49$)$ & $0.25(0.22$ to 0.28$)$ & 0.68 (0.63 to 0.73$)$ \\
\hline 1995 & $2.8(2.7$ to 2.9$)$ & $3.0(2.8$ to 3.1$)$ & 2.5 (2.4 to 2.7 ) & $1.8(1.7$ to 1.9$)$ & $1.9(1.8$ to 2.0$)$ & $1.7(1.6$ to 1.9$)$ \\
\hline 2000 & $5.3(5.2$ to 5.4$)$ & $6.4(6.2$ to 6.6$)$ & 4.2 (4.0 to 4.3 ) & 3.7 (3.6 to 3.8 ) & $4.3(4.1$ to 4.5$)$ & 3.1 (2.9 to 3.2 ) \\
\hline 2005 & $8.1(8.0$ to 8.3$)$ & $10.2(9.9$ to 10.4$)$ & 6.1 (5.9 to 6.3$)$ & 5.8 (5.7 to 5.9 ) & $7.0(6.8$ to 7.2$)$ & 4.5 (4.4 to 4.7$)$ \\
\hline 2010 & $11.8(11.6$ to 12.0$)$ & $15.2(14.9$ to 15.5$)$ & 8.5 (8.3 to 8.7$)$ & 8.7 (8.6 to 8.9$)$ & $10.9(10.8$ to 11.2$)$ & 6.5 (6.3 to 6.7$)$ \\
\hline $\begin{array}{l}\mathrm{p} \text { Trend test* } \\
A / /\end{array}$ & $<0.001$ & $<0.001$ & $<0.001$ & $<0.001$ & $<0.001$ & $<0.001$ \\
\hline \multicolumn{7}{|l|}{ Obesity } \\
\hline 1985 & $0.10(0.10$ to 0.11$)$ & $0.14(0.13$ to 0.16$)$ & 0.05 (0.04 to 0.06$)$ & $0.03(0.02$ to 0.03$)$ & 0.03 (0.03 to 0.04$)$ & $0.03(0.02$ to 0.03$)$ \\
\hline 1995 & 0.98 (0.93 to 1.02$)$ & $1.5(1.4$ to 1.5$)$ & $0.48(0.44$ to 0.53$)$ & $0.44(0.41$ to 0.46$)$ & $0.60(0.55$ to 0.64$)$ & $0.27(0.24$ to 0.31$)$ \\
\hline 2000 & $2.2(2.1$ to 2.3$)$ & 3.4 (3.3 to 3.5$)$ & $1.0(1.0$ to 1.1$)$ & $1.1(1.0$ to 1.1$)$ & $1.6(1.6$ to 1.6$)$ & 0.57 (0.53 to 0.62$)$ \\
\hline 2005 & $3.3(3.2$ to 3.4$)$ & $5.2(5.0$ to 5.3$)$ & $1.5(1.4$ to 1.6$)$ & $1.6(1.6$ to 1.7$)$ & 2.3 (2.3 to 2.4$)$ & 0.85 (0.80 to 0.91$)$ \\
\hline 2010 & $4.3(4.3$ to 4.4$)$ & $6.9(6.7$ to 7.0$)$ & $1.8(1.8$ to 1.9$)$ & 2.2 (2.1 to 2.2$)$ & $3.3(3.2$ to 3.4$)$ & $1.0(1.0$ to 1.1$)$ \\
\hline $\mathrm{p}$ Trend test ${ }^{\star}$ & $<0.001$ & $<0.001$ & $<0.001$ & $<0.001$ & $<0.001$ & $<0.001$ \\
\hline \multicolumn{7}{|c|}{ Overweight+obesity } \\
\hline 1985 & $1.1(1.1$ to 1.1$)$ & $1.1(1.0$ to 1.1$)$ & $1.1(1.1$ to 1.2$)$ & 0.67 (0.64 to 0.69$)$ & 0.57 (0.54 to 0.60$)$ & $0.77(0.73$ to 0.81$)$ \\
\hline 1995 & $5.2(5.1$ to 5.3$)$ & $6.3(6.2$ to 6.5$)$ & 4.0 (3.9 to 4.2$)$ & $3.6(3.5$ to 3.7$)$ & $4.2(4.1$ to 4.4$)$ & $2.9(2.8$ to 3.0$)$ \\
\hline 2000 & $9.2(9.1$ to 9.3$)$ & $11.8(11.7$ to 12.0$)$ & $6.5(6.4$ to 6.7$)$ & $6.7(6.5$ to 6.8$)$ & $8.4(8.2$ to 8.5$)$ & $4.9(4.8$ to 5.1$)$ \\
\hline 2005 & $12.4(12.2$ to 12.5$)$ & 16.1 (15.9 to 16.3$)$ & 8.6 (8.4 to 8.7$)$ & $9.2(9.1$ to 9.3$)$ & $11.8(11.7$ to 12.0$)$ & 6.5 (6.4 to 6.7$)$ \\
\hline 2010 & $15.4(15.3$ to 15.6$)$ & $20.2(20.0$ to 20.4$)$ & 10.7 (10.5 to 10.9$)$ & $11.6(11.5$ to 11.8$)$ & 15.1 (14.9 to 15.3$)$ & $8.2(8.0$ to 8.4$)$ \\
\hline $\mathrm{p}$ Trend test* & $<0.001$ & $<0.001$ & $<0.001$ & $<0.001$ & $<0.001$ & $<0.001$ \\
\hline
\end{tabular}

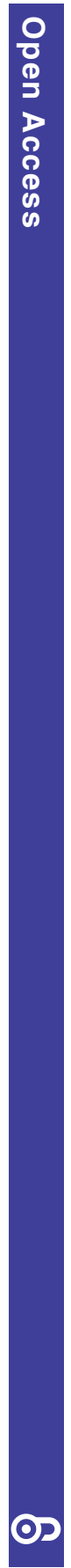




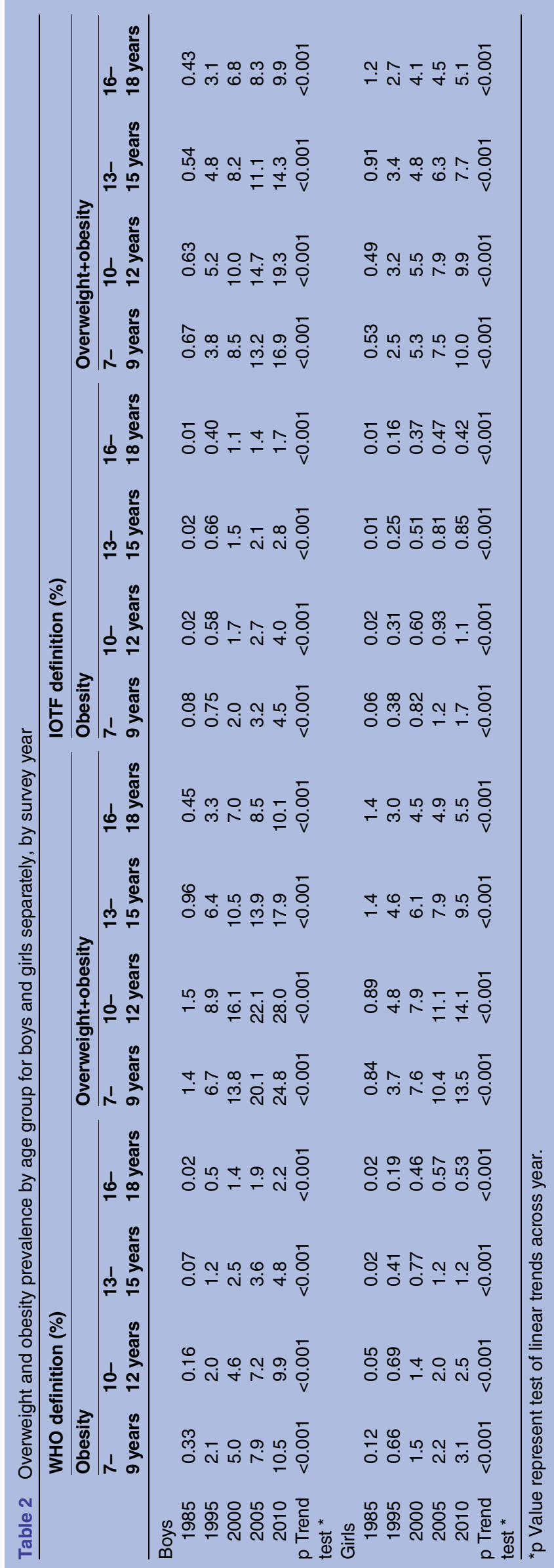

to $17.4 \%$, respectively, between 1991 and 2003 . Meanwhile, the corresponding prevalence among girls increased from $11.1 \%$ to $13.4 \%$ and from $3.1 \%$ to $4.1 \%$, respectively. ${ }^{24}$ Although the definition of obesity differed, our previous study which focused on Chinese urban children also found a significantly greater increasing trend of obesity prevalence in boys and girls, and the PORs associated with gender increased over time in all age subgroups. ${ }^{11}$ Based on the previous studies, we found that gender disparity in obesity and overweight prevalence had different characteristics among different populations, which suggests the need to develop contextspecific public health strategies.

As genetic drifts are unlikely to occur within 25 years, the variation of gender differences in obesity and overweight was most likely due to changes in other factors. Perception of obesity could partly contribute to the gender differences in obesity and overweight. According to Chinese cultural tradition, overweight or obesity is not regarded negatively, but, rather is viewed as good health, especially in boys. Elderly people prefer larger infants and regard overweight boys as stronger individuals. ${ }^{25}$ Many parents are unaware of their children's overweight or obese status, and some parents are more likely to underestimate the weight status of their sons compared with their daughters. ${ }^{25}{ }^{26}$ Owing to such factors, Chinese boys may generally have a different selfconcept of body image compared with Western boys, ${ }^{27}$ and overweight or obesity in boys is not recognised as detrimental or unbearable. On the other hand, Chinese girls prefer a slender shape, ${ }^{28}$ and they are more likely to control their weight compared with their male counterparts. Moreover, changes in lifestyle may contribute to the gender disparity in obesity and overweight as well. The China Health and Nutrition Surveys found that the prevalence of screen time $\geq 2$ hours/day increased from $11.2 \%$ in 1997 to $44.3 \%$ in 2006 among urban boys aged $13-18$ years, while it increased from $9.7 \%$ to $34.7 \%$ in the same period among urban girls. ${ }^{29}$ China has already developed some guidelines to control general childhood obesity, such as Guidelines on Snacks for Chinese Children and Adolescents (published in 2008) ${ }^{30}$ and the School-age Children and Teenagers Overweight and Obesity Prevention and Control Guidelines (issued in 2007). ${ }^{31}$ However, these guidelines did not consider gender differences. Gender specific preventive guidelines and public health policies for childhood obesity should be formulated in the future. Considering that less physical activity was also closely related to overweight and obesity among Chinese school-aged students, ${ }^{32}$ we suggest separating girls and boys for the physical education class, which despite its lack of popularity in many schools, would increase the boys' exercise $^{33}$ and create supporting environments to encourage both boys and girls to take part in physical activities.

Most developed countries reported that children residing in rural areas had a higher risk of overweight and obesity compared with children residing in urban areas, ${ }^{34}$ 

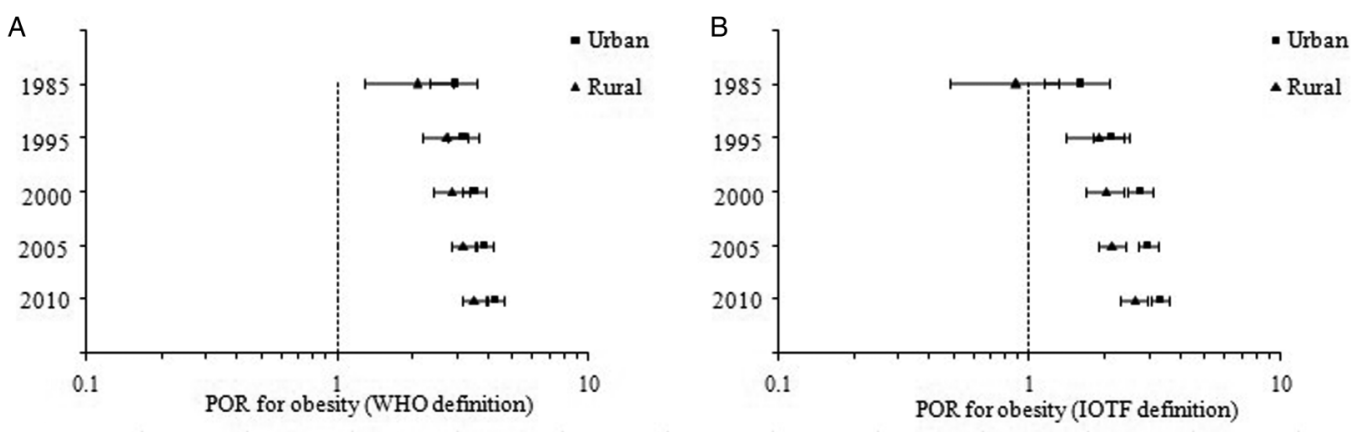

C
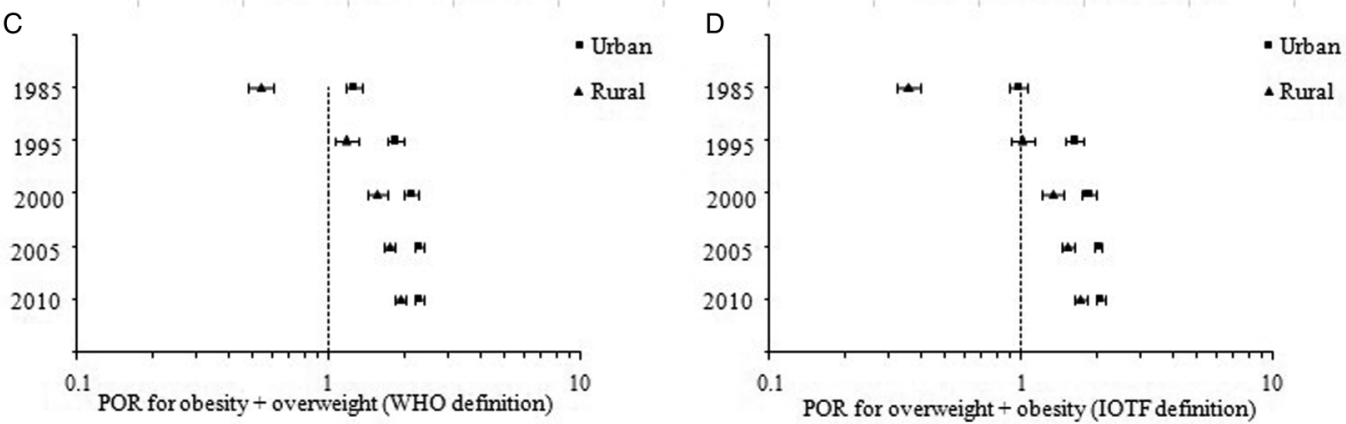

Figure 1 Prevalence ORs (POR) with $95 \% \mathrm{Cl}$ for obesity and overweight of boys compared with girls in different year of CNSSCH by urban-rural areas, adjusted for age, socioeconomic status, and school. (A) shows PORs for obesity of gender disparity by using WHO definition. (B) shows PORs for obesity of gender disparity by using IOTF definition; (C) shows PORs for obesity and overweight of gender disparity by using WHO definition; and (D) shows PORs for obesity and overweight of gender disparity by using IOTF definition. CNSSCH, Chinese National Survey on Students's Constitution and Health; IOTF, International Obesity Task Force.

while developing countries reported the opposite. ${ }^{35}$ In the present study, we found that the prevalence of obesity and overweight was higher in urban than rural children, which was consistent with reports from India and Brazil. ${ }^{35}$ In line with previous studies, we found that the gender difference in obesity and overweight prevalence was larger among urban than rural children. This difference between urban and rural areas may be associated with differences in exposure to obesogenic environmental factors, ${ }^{37}$ such as access to high-energy-density foods and less physical activity, both of which are more common among urban children than their rural counterparts. ${ }^{38}$ However, with increasing urbanisation and the convergence of lifestyles between urban and rural areas, the pace of obesity prevalence has become more rapid in rural areas over time. ${ }^{22}$ This may contribute to diminishing gender disparities in PORs between urban and rural areas. Therefore, policymakers and experts should develop gender-specific interventions for obesity, and also consider the urban-rural disparities. Policymakers should not neglect the obesity epidemic in rural populations, although their obesity prevalence is still lower than that in urban populations. However, considering that absolute burden is still considerably higher in urban areas given the prevalence as well as the population distribution, obesity prevention and control should be advocated in urban areas of China.

The current study uses data from the largest nationally representative survey of Chinese school-aged children to date. However, the study has several limitations. First, the
CNSSCH data collection was carried out in schools and therefore, some 15-18-year-old adolescents who could not attend senior high school, mainly in rural areas, were excluded from our sample. ${ }^{39}$ However, similar patterns were observed among all five surveys, even after stratification by urban-rural area. Second, the absence of detailed information at the individual level, such as family income, parents' BMI and number of siblings, may have posed limitations. However, some studies reported that gender was an independent factor for childhood obesity when family income, parents' BMI and the number of siblings were adjusted for. ${ }^{11} 40-42$

\section{CONCLUSION}

In summary, this study observed a dramatic increase in the prevalence of childhood obesity and overweight in Chinese boys and girls, with the prevalence in boys making a larger contribution to the rapid increase than the prevalence in girls. Although urban boys should be the key target of obesity prevention, more attention should be paid to rural boys, since the pace of the obesity epidemic in rural areas was much faster.

Author affiliations

${ }^{1}$ Institute of Child and Adolescent Health, School of Public Health, Peking University, Beijing, China

${ }^{2}$ Division of Social Medicine and Global Health, Department of Clinical Sciences, Lund University, Malmö, Sweden

${ }^{3}$ Centre for Chronic Disease, School of Medicine, University of Queensland, Royal Brisbane \& Women's Hospital, Herston, Queensland, Australia 
Acknowledgements The authors thank WK Liao, WH Xing and X Zhang for their permission to access the 1985, 1995, 2000, 2005 and 2010 Chinese National Survey on Student's Constitution and Health data. The authors also thank the students who participated in the surveys for their cooperation.

Contributors YS conceived and designed the study, carried out the initial analyses and prepared the first draft of the manuscript. JM, H-JW, BD, ZW and AA critically reviewed and revised the manuscript. YS and JM conducted the research and collected the data. ZW, BD and AA interpreted data, developed materials and tools for analysis and revised the manuscript. All authors read and approved the final manuscript.

Funding The present study was supported by a grant from the National Natural Science Foundation of China (81302442) awarded to YS.

Competing interests None declared.

Patient consent Obtained.

Ethics approval The project was approved by the Medical Research Ethics Committee of Peking University Health Science Center (IRB00001052-13082).

Provenance and peer review Not commissioned; externally peer reviewed.

Data sharing statement No additional data are available.

Open Access This is an Open Access article distributed in accordance with the Creative Commons Attribution Non Commercial (CC BY-NC 4.0) license, which permits others to distribute, remix, adapt, build upon this work noncommercially, and license their derivative works on different terms, provided the original work is properly cited and the use is non-commercial. See: http:// creativecommons.org/licenses/by-nc/4.0/

\section{REFERENCES}

1. Lobstein T, Jackson-Leach R, Moodie ML, et al. Child and adolescent obesity: part of a bigger picture. Lancet 2015;385:2510-20.

2. Dehghan M, Akhtar-Danesh N, Merchant AT. Childhood obesity, prevalence and prevention. Nutr J 2005;4:24.

3. Wang Y, Lim H. The global childhood obesity epidemic and the association between socio-economic status and childhood obesity. Int Rev Psychiatry 2012;24:176-88.

4. Han JC, Lawlor DA, Kimm SY. Childhood Obesity-2010: progress and challenges. Lancet 2010;375:1737-48.

5. Song $\mathrm{Y}$, Wang $\mathrm{HJ}$, Ma J, et al. BMl-for-age Z-score distribution shifts among Chinese children: gender disparity. Obesity (Silver Spring) 2014;22:1187-93.

6. $\mathrm{Ng} \mathrm{M}$, Fleming $\mathrm{T}$, Robinson $\mathrm{M}$, et al. Global, regional, and national prevalence of overweight and obesity in children and adults during 1980-2013: a systematic analysis for the Global Burden of Disease study 2013. Lancet 2014;384:776-81.

7. National Obesity Observatory. International Comparisons of Obesity Prevalence. [WWW document]. 2015. http://www.noo.org.uk/NOO about_obesity/child_obesity/international

8. Gupta DK, Shah P, Misra A, et al. Secular trends in prevalence of overweight and obesity from 2006 to 2009 in urban Asian Indian adolescents aged 14-17 years. PLOS ONE 2011;6:e17221.

9. Borders TF, Rohrer JE, Cardarelli KM. Gender-specific disparities in obesity. J Community Health 2006;31:57-68.

10. Chen TJ, Modin B, Ji CY, et al. Regional, socioeconomic and urban-rural disparities in child and adolescent obesity in China: a multilevel analysis. Acta Paediatr 2011;100:1583-9.

11. Song $\mathrm{Y}$, Wang $\mathrm{HJ}, \mathrm{Ma} \mathrm{J}$, et al. Secular trends of obesity prevalence in urban Chinese children from 1985 to 2010: gender disparity. PLOS ONE 2013;8:e53069.

12. CNSSCH Association. Report on the 2010th National Survey on Students' Constitution and Health. Beijing: China College \& University Press, 2012 (in Chinese).

13. CNSSCH Association. Report on the 1985th National Survey on Students' Constitution and Health. Beijing: People's Education Publishing, 1987 (in Chinese).

14. CNSSCH Association. Report on the 1995th National Survey on Students' situation and Health. Changchun: Jilin Technical and Science Publication, 1997 (in Chinese).

15. CNSSCH Association. Report on the 2000th National Survey on Students' Constitution and Health. Beijing: China College \& University Press, 2002 (in Chinese).
16. CNSSCH Association. Report on the 2005th National Survey on Students' Constitution and Health. Beijing: China College \& University Press, 2007 (in Chinese).

17. Ji CY, WGOC. Body mass index reference for screening overweight and obesity in Chinese school-age children. Biomed Environ Sci 2005;18:390-400

18. World Health Organization. WHO Reference 2007 SPSS macro package. [WWW document]. 2007. http://www.who.int/entity/ growthref/tools/readme_spss.pd

19. de Onis M, Onyango AW, Borghi E, et al. Development of a WHO growth reference for school-aged children and adolescents. Bull World Health Organ 2007;85:660-7.

20. Cole TJ, Bellizzi MC, Flegal KM, et al. Establishing a standard definition for child overweight and obesity worldwide: international survey. BMJ 2000;320:1240-5

21. Liang $Y J, X i B$, Song $A Q$, et al. Trends in general and abdominal obesity among Chinese children and adolescents 1993-2009. Pediatr Obes 2012;7:355-64.

22. Song $\mathrm{Y}, \mathrm{Ma} \mathrm{J}$, Wang HJ, et al. Secular trends of obesity prevalence in Chinese children from 1985 to 2010: Urban-rural disparity. Obesity (Silver Spring) 2015;23:448-53.

23. Fan S, Cohen MJ. Critical choices for China's agricultural policy. 2020 Brief: No. 60. [WWW document]. 1999. http://www.ifpri.org/ sites/default/files/publications/vb60.pdf

24. Liou TH, Huang YC, Chou P. Prevalence and secular trends in overweight and obese Taiwanese children and adolescents in 19912003. Ann Hum Biol 2009;36:176-85.

25. Li J, Lei J, Wen S, et al. Sex disparity and perception of obesity/ overweight by parents and grandparents. Paediatr Child Health 2014;19:e113-16

26. Lundahl A, Kidwell KM, Nelson TD. Parental underestimates of child weight: a meta-analysis. Pediatrics 2014;133:e689-70.

27. Marsh HW, Hau KT, Sung RY, et al. Childhood obesity, gender, actual-ideal body image discrepancies, and physical self-concept in Hong Kong children: cultural differences in the value of moderation. Dev Psychol 2007;43:647-62.

28. Leung F, Lam S, Sze S. Cultural expectations of thinness in Chinese women. Eat Disord 2001;9:339-50.

29. Cui Z, Hardy LL, Dibley MJ, et al. Temporal trends and recent correlates in sedentary behaviours in Chinese children. Int $J$ Behav Nutr Phys Act 2011;8:93

30. Guidelines on snacks for Chinese children and adolescents. Acta Nutrimenta Sinica 2008;30:123-4. [In Chinese].

31. Wang $\mathrm{H}$, Zhai F. Programme and policy options for preventing obesity in China. Obes Rev 2013;14(Suppl 2):134-40.

32. Zhang X, Song Y, Yang TB, et al. Analysis of current situation of physical activity and influencing factors in Chinese primary and middle school students in 2010. Chin J Prev Med2012;46:781-9.(in Chinese).

33. Song Y, Ma J, eds. Activity instruction on physical education and extra-curricular sport among children and adolescents-collection of aerobic exercise prescription. Beijing: Peking University Medical Science Press, 2013. (In Chinese).

34. Davis AM, Bennett $\mathrm{KJ}$, Befort $\mathrm{C}$, et al Obesity and related health behaviors among urban and rural children in the United States: data from the National Health and Nutrition Examination Survey 20032004 and 2005-2006. J Pediatr Psychol 2011;36:669-76.

35. Saraswathi YS, Najafi M, Gangadhar MR, et al. Prevalence of childhood obesity in school children from rural and urban areas in Mysore, Karnataka, India. J Life Sci 2011;3:51-5.

36. Wang Y, Lobstein T. Worldwide trends in childhood overweight and obesity. Int J Pediatr Obes 2006;1:11-25.

37. Washington RL. Evidence-based medicine and the obesogenic environment. J Pediatr 2006;149:5-6.

38. Dearth-Wesley T, Wang H, Popkin BM. Under- and overnutrition dynamics in Chinese children and adults (1991-2004). Eur J Clin Nutr 2008;62:1302-7.

39. Ji CY, Cheng TO. Epidemic increase in overweight and obesity in Chinese children from 1985 to 2005 . Int J Cardiol 2009, 132:1-10.

40. Martin KS, Ferris AM. Food insecurity and gender are risk factors for obesity. J Nutr Educ Behav 2007;39:31-6.

41. Babey SH, Hastert TA, Wolstein J, et al. Income disparities in obesity trends among California adolescents. Am J Public Health 2010;100:2149-55

42. Keane $\mathrm{E}$, Layte $\mathrm{R}$, Harrington $\mathrm{J}$, et al. Measured parental weight status and familial socio-economic status correlates with childhood overweight and obesity at age 9. PLOS ONE 2012;7: e43503. 